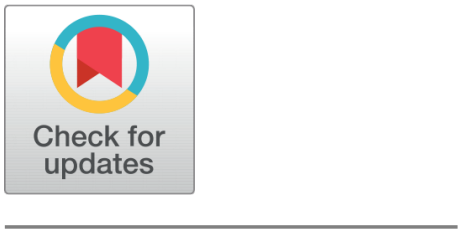

G OPEN ACCESS

Received: 03-04-2020

Accepted: 16-05-2020

Published: $30-05-2020$

Editor: Dr. Natarajan Gajendran

Citation: Moghimi SM, Dashti R, Bostani A (2020) Studying the challenges and obstacles of the privatization of electricity distribution companies. Indian Journal of Science and Technology 13(14): 1512-1522. https://doi.org/ 10.17485/IJST/v13i14.121113_492

* Corresponding author. Seyed Morteza Moghimi

R \& D Research Scientist, MicrowaveSoft Inc, Montreal, QC, Canada

morteza.moghimi@microwavesoft.com

Funding: None

Competing Interests: None

Copyright: $\Subset 2020$ Moghimi, Dashti, Bostani. This is an open access article distributed under the terms of the Creative Commons Attribution License, which permits unrestricted use, distribution, and reproduction in any medium, provided the original author and source are credited.

Published By Indian Society for Education and Environment (iSee)

\section{Studying the challenges and obstacles of the privatization of electricity distribution companies}

\author{
Seyed Morteza Moghimi ${ }^{1}{ }^{*}$, Reza Dashti ${ }^{2}$, Ali Bostani ${ }^{3}$ \\ 1 R \& D Research Scientist, MicrowaveSoft Inc, Montreal, QC, Canada \\ 2 Assistant Professor, School of Advanced Technologies, University of Science and \\ Technology, Tehran, Iran \\ 3 Associate Professor, Department of Electrical and Computer Engineering, American \\ University of Kuwait, Salmiya, Kuwait
}

\section{Abstract}

Background/Objectives: In the past couple of decades, several counties all around the globe, decided to conduct some reforms in the way that they manage the electrical power in their countries. Even in Middle East countries like Iran have taken the path to intensively privatize their power distribution and pass it over to the non-governmental sector paving way for security, social and economic threats. For this purpose, lack of proper and optimal management results in distribution companies and the government having to explain its threats so that sovereignty could eliminate the threats or reduce their effects. This study discusses the problems of restructuring the electric power sectors and its defects in Iran distribution companies. Methods/Statistical analysis: This paper discusses the problems of re-structuring the electrical power sectors and its defects in the distribution companies. Furthermore, this paper investigates the threats facing the privatization of electricity distribution companies. The threat of monopolization is also analysed in a separate section. Data source gathering is done during 2014-2016. Findings: Establishment of formal and legal framework in this regard is provided in such a way that the interests of all stakeholders, including shareholders, employees, subscribers, and government are provided. Application/Improvements: Establishment of formal and legal framework in this regard is provided in such a way that the interests of all stakeholders, including shareholders, employees, subscribers, and government are provided. Also, establishment of proper implementation of the privatization of electricity distribution companies in Iran.

Keywords: Iran distribution companies; Electricity distribution company; Monopoly; Privatization; Distribution systems.

\section{Introduction}

Electric power distribution is the final level of the electricity supply chain. From this point of view, structure and functions of distribution companies are very important for 
consumers' satisfaction and the economic sustainability of the power industry ${ }^{(1-6)}$.

Liberalization, privatization, deregulation and devolution of government functions to the private sector are all categories that in recent decades have been regarded by economists and policy-makers, and they are considered as a way to rationalize the economic structure of society, adjusting the size of government, mobilizing private funds, increasing the efficiency of the companies and reducing the burden of government services. One of the macroeconomic problems in the industrialized countries and developing countries connected to the privatization is industry-related infrastructure. In the decades 1970-90 the government's ineffectiveness in providing optimal infrastructure services led the overall inference that the government failed to fulfill the assigned tasks well. So that policymakers thought to use the private sector in industry and related services. One of the energy carriers that is the guarantor of the country's economic activity and is always a strategic tool for governments is electricity ${ }^{(7-12)}$.

In the past three decades, liberalization in the electricity sector has rapidly advanced and a number of reforms have been introduced in a number of countries throughout the world. The main motivation behind those reforms has been efficiency gains leading to cost reductions, which are assumed to benefit consumers through price reductions and improvements in the quality of service ${ }^{(13)}$ Many papers and research have been written on power sector reforms in developed and developing countries (see for example $\left.{ }^{(14-18)}\right)$. The great majority of these studies have concentrated on the reforms in Asian and Latin American countries, while fewer studies dealt with western Asia and Iran ${ }^{(19)}$.

Privatization, defined as the transfer of ownership of state-owned enterprises (SOEs) to private shareholders, has resulted in important structural changes worldwide over the last two to three decades. It's expected that before commencing the process of privatization, the infrastructures are prepared so that the private specialized companies with higher authority to manage the system become the owners of the corporations, and provide better services at a lower cost, rather than creating opportunities for semi-private organizations to deprive government of applying its authority (The report of the Commission of $44^{\text {th }}$ constitutional article on December 2011 in the parliament proves it). Monopoly in all kinds of improper privatization may prevent the realization of the above objective. Thus, changing the nature of activities in the private sector may result in poor service, less productivity and efficiency of national resources. Privatization threats may affect not only the social and economic areas but also security, especially in the realm of passive defense. The Iranian electricity distribution networks have not been studied in-depth from the perspective of passive defense yet, and they have many weaknesses and vulnerabilities in the face of new and even classical threats. Considering the current situation of electricity distribution networks from the perspective of passive defense, privatization of electricity distribution companies and the transfer of the management of its activities to the private sector would be highly sensitive ${ }^{(13)}$.

In the paper, the weaknesses and threats faced by the system and the governance of privatization and the government role and solutions are clarified. In all sections of the paper, threats are dealt with from both the socio-economic aspect and a security one. Here, the inherent features of distribution systems and the complexities of managing distribution companies are discussed to clarify the consequences of mismanagement of such companies. Then, government duties and obligations are discussed so that correct policies of privatization are sketched. After that, the characteristics and disadvantages of monopoly will be discussed. Finally, the privatization process of electricity distribution companies in Iran is reviewed and section 5 concludes the paper.

\subsection{Electricity Distribution Structure}

Since restructuring of electricity supply industry (for example, electrical distribution mentioned in Figure 1 ), whose goal was introducing competition between participants of electricity supply chain, the components which are natural monopoly should have been separated from competitive components. The separation of generation from transmission network and distribution network operation from electricity supply is such a strategy which is called unbundling. The structures of electricity supply industry before and after restructuring has been shown in Figure 2.

The subjects which have been discussed in this section are the causes, methods and the steps required for separation of distribution network operation and electricity supply.

Unbundling of electricity distribution and supply could be beneficial for both consumers and power industry. From power industry point of view, unbundling will separate economic activities of different parts, so that the managers of each part could concentrate on their own business which enhances the efficiency and increases the profitability. From final consumers' point of view, unbundling in electricity distribution will bring about a more competitive environment that leads to reduction in customers' costs. 


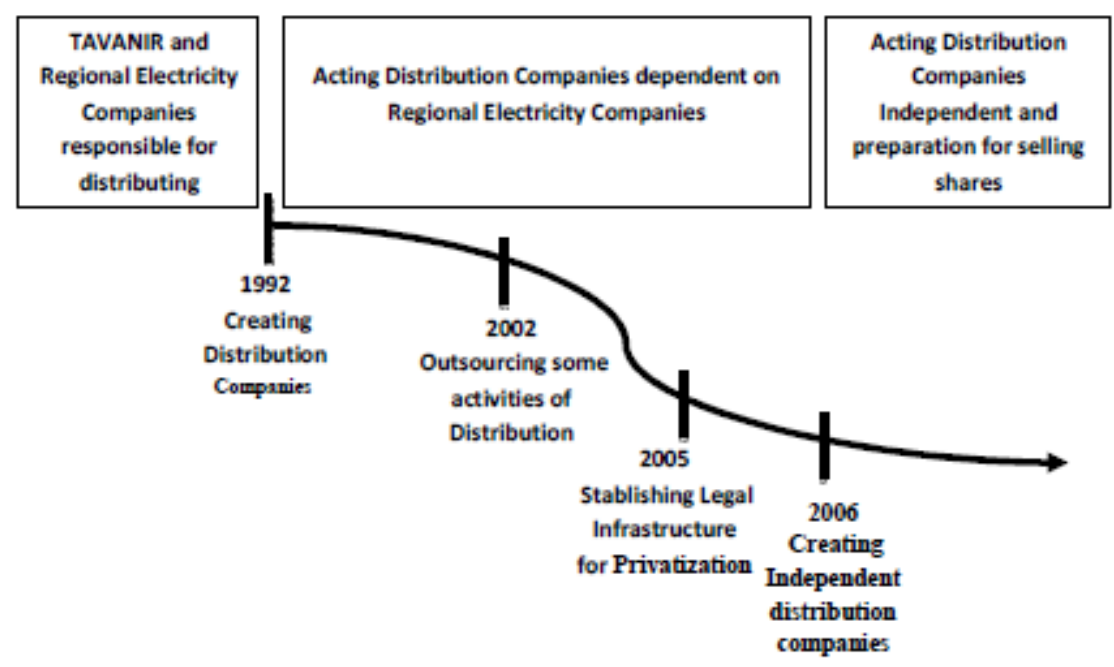

Fig 1. Changing of electrical distribution sector in $\operatorname{Iran}^{(20)}$

\section{Before Restructing}
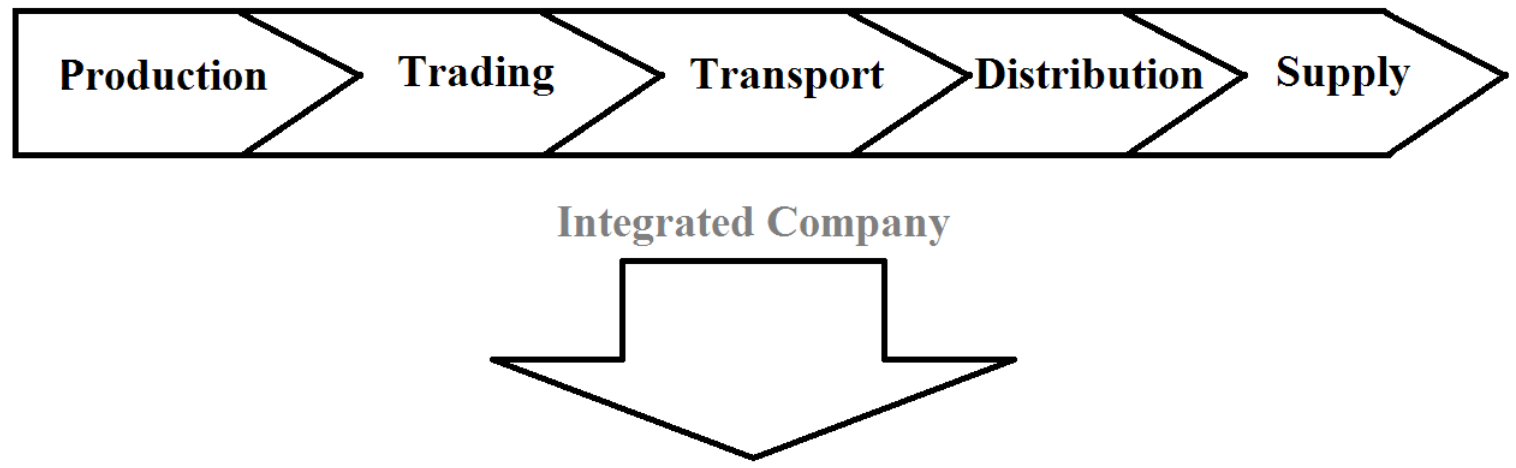

After Restructing

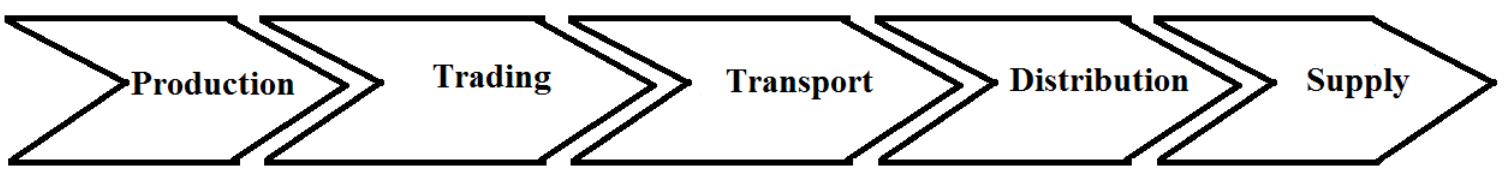

Fig 2. Structures of electricity supply industry before and after restructuring ${ }^{(1)}$

\subsection{The Effects of Electricity Distribution Companies Mismanagement}

Electricity distribution companies have huge and distributed assets. The distribution system is vulnerable to many geographical, social, economic, political and other factors. Each of these assets is in contrast to the assets of generation and transmission includes a simpler technology, as well as less impact and cost. Despite the stated points, for various reasons, power distribution systems have particular importance in the power industry as follows: Energy distribution companies with the responsibility of getting the dues are in charge of providing the revenue of the electricity industry. However, the loss distribution is done in the power industry. Because of the diverse activities of the distribution companies, the power industry personnel are active in this sector. The most important feature of the electricity distribution system is that its assets are not competitive. This feature does not allow simultaneous distribution of two companies in the same geographic area to offer their services. This feature shows 
the inherent monopoly of electricity distribution network assets. A lack of proper management of power distribution systems leads to regional and national impacts. In each sub-part of a distribution system, mismanagement causes some negative effects on productivity and economic indicators first, and if intensified, some security threats second. The latter is more likely when all power distribution is owned by one company; for mismanagement is applied to all Iranian distribution systems, especially considering that the political tendencies are also manifested in the company.

- Energy distribution companies are the biggest consumers of fuel and energy resources (to sell electricity to the clients and compensate the system's wastes) (mentioned in Figure ${ }^{3}$ ), and are also the consumers of copper, aluminum, cement, etc. (to establish the construction's properties). However, the loss distribution is done in the power industry. Because of the diverse activities of the distribution companies, the power industry personnel are active in this sector.

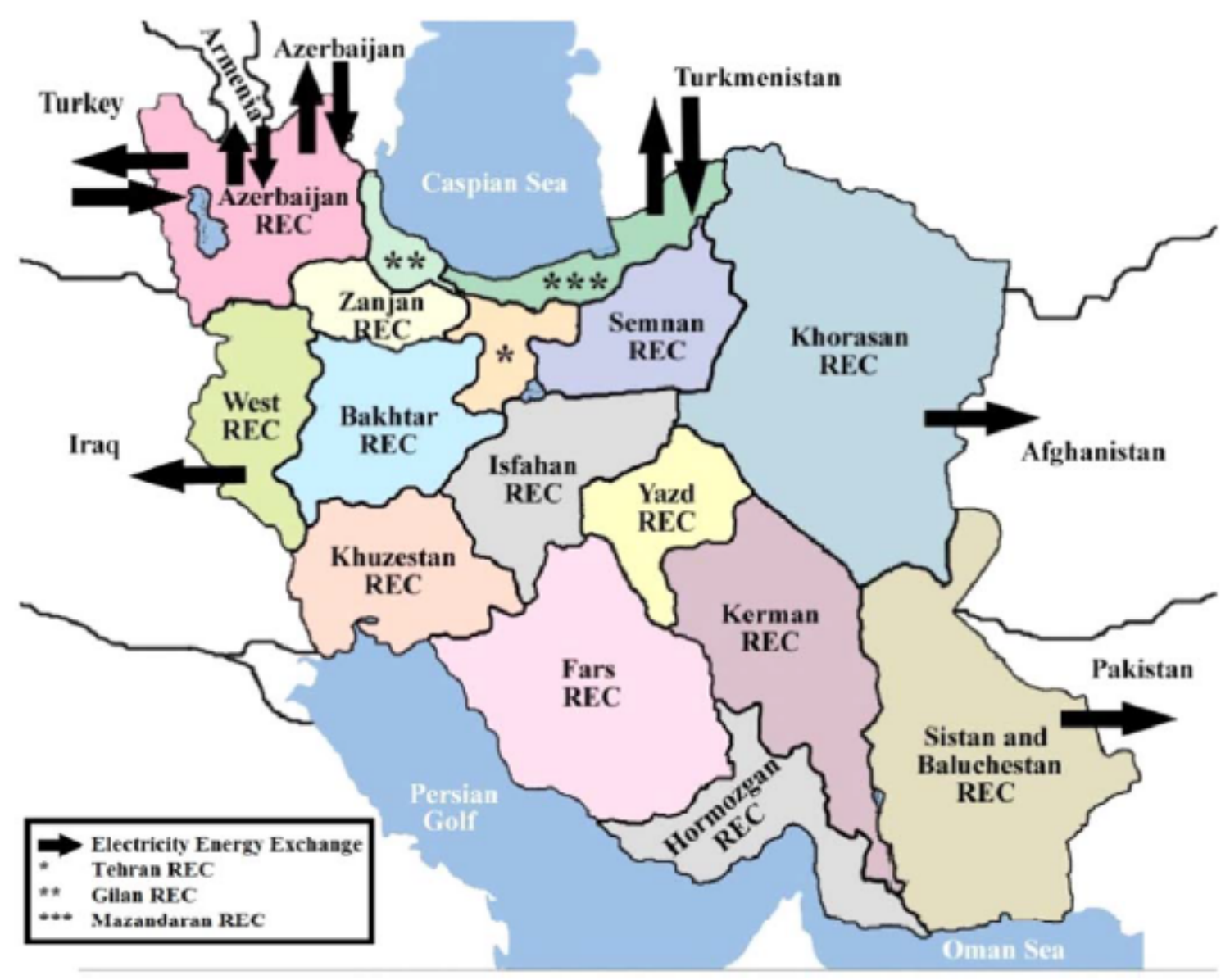

Fig 3. Geographical locations of RECs and across border exchanges of electricity in

Iranian electricity industry ${ }^{(21)}$

- Lack of monitoring and investment in the electricity distribution network has led to a decrease in the quality of electric services, including increased blackouts, with poor and non-standard voltage being delivered to consumers and jeopardy of network equipment.

- Electricity distribution companies have to deal with different local agencies and institutions, such as municipalities, water and sewage companies, telephone companies, gas companies and so on, so that without such interaction, urban and regional projects would be hardly done and their cost increases. Also, regional and national projects would be dismantled.

- Not following the receipt of subscriber bills (for electricity) by the electricity distribution companies will reducing the most important revenues in the electricity industry.

- Development contractors, improvement and customer service, as well as equipment manufacturers are very much dependent on the budgeting policies and allocation of liquidity in the electricity distribution companies. 
- Employees of the electricity distribution companies require proper motivation to improve the efficiency and productivity of their operations. Poor management of distribution companies causes dissatisfaction and loss of motivation of human resources.

- Due to the strength and development of intelligent infrastructure, and because the development of distributed generation, renewables etc., the private sector has ensured economic and financial interests. This requires legislation be implemented by the government. Lack of attention to the strengthening of the infrastructure of the electricity distribution companies will continue to manage traditional and digital economy and future response to growing expectations of society.

- A good performance in times of crisis and disaster such as floods and earthquakes requires careful planning, monitoring and controlling of assets and geographic distribution in the areas of strengthening the infrastructure before the crisis. In the case of negligence or lack of attention to all the above, a disastrous crisis can deepen and various social problems then occur. According to the electricity supply after the crisis, the development of infrastructure facilitates by the management is of high importance.

- Strengthening the infrastructure and systems, including the assets necessary to prevent and reduce the depth of the crisis, is a passive defense. Failure to do so could cause the vulnerability of natural systems and networks against the increase of external attacks.

The Sovereignty Duties and Responsibilities in Electricity Distribution Companies

The state-run distribution companies, distribution companies that transfer management to the private sector, transfer of ownership of the electricity distribution companies, power distribution companies and transfer of component activities and analysis activities, etc., are examples of these models, each with numerous advantages and disadvantages. But in any case, it is a model where sovereignty can better perform their duties. Governance responsibilities can be divided into five categories.

\subsection{Planning}

The privatization of government functions to change the structure of government in planning will lead to planning. Any type of privatization is part of government planning and management of the private sector. Related laws should be developed and adjusted so that the interests of the private sector in line with the interests of the government are fulfilled. In this case, planning the programming of the private sector should be the rule. Set rules to ensure the necessary alignment of interests is inevitable in this section.

\subsection{Organizing and coordinating}

Organizing and coordinating are two separate issues, so that the structure, powers, jurisdiction and responsibilities identified characterize the relations between them. In order to influence the private sector and the authorities and responsibilities, the relationships between different parts of the private sector, the role of small power plants, distributed and renewable energy, resellers, contractors and builders, as well as owners and managers in this sector are determined. The relationship between each of the actors and the government must be identified and explained. The relationship is between the actors so that they do not overlap and cannot take any abuse. Thus, the private sector is forced to plan in accordance with government expectations. How privatization works, as a result of the coordination between actors determines the decisive role in defining the relationships and rules as well. How privatization should be so corrupt? Tally the lowest and the least overlap and minimize the possibility of conflict actors.

\subsection{Monitoring}

Three methods for monitoring the implementation of the electricity distribution companies are:

The first method is the intelligent building system: In this case, the system automatically reports its status. The continuous monitoring of the performance of each player can be evaluated. Many of them have not been implemented. The second method is the creation of companies. These companies work directly under the rule of the duty to collect and store information and provide information to the actors (with regard to access restrictions) and so on. Such companies must be independent in terms of data collection. But it is noteworthy that many of the actors in the electricity distribution system, for example, cutoff information recorded by the distribution companies, the analysis and follow-up. Since cutoff information shows the efficiency of distribution companies, information companies can be efficient in this section. The third method is the set of rules as the beneficiary. This issue deals with the presumption that all beneficiaries with all information at its disposal, should be provided with a fair method to prove his claim to the rights interest. In order to help study the cost and risks, and crime rates set by government shareholders. Then appropriate legislation will be the possibility of rights for all players. The law requires a comprehensive framework of possible differences between actors, by providing information and proving them. The role of free media and independent information provided by the government should also create an appropriate atmosphere to be seriously 
active. Certainly, each of the above methods in any privatization of a different nature and infrastructure needs are many and varied.

\subsection{Control}

The purpose of this section is to ensure achieving the goals of governance over time. Over time, the predictions are met with distortion. Environmental and social conditions have changed and may face disaster. Therefore, government should monitor the later stage and take corrective measures when appropriate. Corrective actions can include modifying rates and fines, endorsement or disqualification and qualification of actors and actresses for motivation or to reduce the risk. Corrective measures performance parameters set electricity distribution companies, distribution system and enhancing the economic and social of the distribution system. Procedures and control processes in many different types of privatization are different. In addition to the above, the most important economic and social changes have a huge impact on the stability of the electricity distribution companies. This shows the variety of risks facing the electricity distribution companies that sought the establishment of correct and optimal sovereignty.

\subsection{The implementation of proper governance requirements and the modernization of electricity distribution companies}

As stated in section three, the rule of electricity distribution companies has several tasks to perform properly and efficiently. They need to fulfill several requirements. These requirements should be considered in the process of the privatization process and their implementation followed up so as to contribute to the success of the privatization of electricity distribution companies are the largest structural change. The purpose of this section outlines the requirements of the proper functions of paid government:

\subsection{Anticipating, Planning and monitoring risks}

Risks facing the distribution system, which is different from such as social behavior (including the amount of use and the treatment of urban facilities), urban planning and municipal activities, decisions, governance, economic status and geographical factors. All risks mentioned affect the cost and quality of services. All these factors simultaneously occur with the operations and activities of the electricity distribution companies as planned. The resolution requires planning and monitoring and, if necessary, to improve rate risks, disqualified players must be considered.

\subsection{Establishment of infrastructure monitoring}

As already mentioned, the needs of structural and legal infrastructure, as well as software and hardware must be monitored. Monitor the activities of government cannot provide minimal infrastructure with a serious disorder.

\subsection{Deciding the difference between sale prices of energy}

Energy is a large part of the sale price to the public subsidy is awarded. Although the state of the electricity distribution companies, the subsidy is equivalent to government services. But after the privatization of the distribution companies, subsidies to convert to the detriment of the private sector and their demands that the government is a serious disruption in the event of non-payment of services. The change in manipulation of rates and price by resorting to tricks as well as increased cost differentials should be taken seriously. As mentioned, management and distribution of high political and social power may offer to purchase government debt to assets and stocks. This purchase is effectively against the competition and creates spaces for the working poor. So, before privatization, the country's energy economy should be reformed at the macro level (parliament, government and the people) are important decisions to be taken.

\subsection{The Presence of tools to monitor the purchase and sale of shares in the private sector}

This will monitor the purchase and sale of shares in order to prevent vertical and horizontal integration in the distribution system, and prevent the sale of shares to foreign owners and are unqualified. Vertical integration means purchasing power is distributed by a company that deals loss at other plants, and vertical integration also means buying shares of competitors and creating a monopoly in distribution. We have to change the constitution as hasty and illegal distribution companies in 2013 occurred. 


\subsection{Stabilization of rates set by the regulatory methods}

The setting of rates, fees and penalties for the private sector, which is determined by the government, the private sector and government, is always controversial. Because the rates must be adjusted so that the adjusted risk can ensure a reasonable profit for the private sector, and attain government objectives. For this purpose, the private sector will inevitably have to cost in investment planning. By changing the setting of rates of investment and degree of improvement expected from measures aimed at governance, change. Clearly, an investment approach results in a less favorable private sector and the promotion of optimal parameters, resulting in optimum customer service. Sovereignty must be a fair way to set criteria and choose and apply planning and control activities.

\subsection{Deciding in yimes of crisis and avoiding any disruption to the security of electricity supply}

In times of crises such as floods, earthquakes, etc., or where security of supply is difficult for many distributed network installations, serious injuries. Can occur. The volume of assets in the event of damage to the high level of private sector interest covers several years. The recognition of the damage of the crisis in many cases, the difference will be a failure due to a lack of maturity or when crises are past. However, in times of war or terrorist movements to power outages, damage to the system requires serious consideration to support the agreement and determine the amount of damages. In such cases, retrofitting a network against external threats will be the subject of a contest between the ruling and the owner. One of the most important requirements is to establish a uniform financial system, procedures and periodic reporting system tailored to the requirements of establishing a transparent and internal control system of financial and performance verification of government that can provide reliable information to the government, which is currently ignored despite the presence of independent auditors.

\subsection{The requirements for proper flow of money}

Lack of a proper flow of private sector money involved in distribution, including distribution companies, local stations, retailers, contractors, suppliers and employees can lead to job seeking and getting some of the actors mentioned lost in the sector. The actors that impair the flow of money from the cash they have accumulated will earn high profits. The problem is so acute that some players cannot get distribution in the bankruptcy. It is important to know when a distribution company is one of the main bottlenecks in the distribution of liquidity and accurate flow of money.

\subsection{Information transparency}

Information management and governance of the private sector is the main tool. Lack of transparency leads to unfair distribution of resources and non-optimal decisions, and sometimes they are wrong. It is necessary to create infrastructure requirements and to ensure transparency of information that is essential for any kind of privatization, including the privatization of the distribution companies. Establishing the requirements for the rules related to the coordination and organization of actors and stakeholders, rules and legal requirements outlining the infringement of its privatization should be considered a crime and judicial authorities can follow up.

\subsection{Commercialization}

Commercialization of economics is always mentioned before privatization. During this stage, the inefficiency of the public sector to the private sector is not transferred. Commercialization means to regulate distribution companies in order to gain maximum profits. In this case, expectations, obstacles and strategies, management and governance status can determine the interaction of risks assessment and do it better. The steps to prepare for work as a distribution company is private. Change management ideas of the government budget to perform tasks with priority based on the electricity market and economic benefit is the most important achievement of this stage.

\subsection{Preventing the creation of monopolies}

Direct or indirect transfer of electricity distribution companies are trusted institutions, leading to a clear vision of the management system similar to the government's safety net. However, it should be kept in mind that the biggest challenge of privatization is monopoly. However, trusted the institution, we have the role of government, but also an actor distribution system and cannot perform the duties of governance. As mentioned previously, it is the responsibility of government to create a sustainable justice system among the players, but each player follows the interests of their firm. The most important requirement for accurate and efficient governance duties prevent monopoly in the management of electricity distribution companies. Although this overview 
has simplified the complexities of diversity, it can have catastrophic effects. In order to better illustrate and explain the disadvantages of monopoly in the privatization of electricity distribution companies, we need to consider all aspects of the monopoly with different views.

\subsection{The monopoly threat in the electricity distribution companies privatization}

In order for the rule to function correctly in electricity distribution companies, we need to realize the most important management of non-monopoly requirements. Although the topics in this chapter are not followed, its consequences are examined in this section. After the transfer, if correctly applied, the rule of institutions and the rule of trust in each side will bargain and will defend their rights. Although these bargain prices are not beneficial as amended, this benefit can be no privatization of the unity government and parliament officials also happens. On the other hand, it is reasonable to have negligible benefit to the multiple disadvantages.

- The private sector severely reduces monopoly bargaining power against the government. This, however, results in correction of prices and removal of subsidies, but the defense also denied the sovereignty of other actors than rival systems. This could have disastrous consequences on the quality of service and the efficiency of the system in the long term. Thus, sustainable justice as the main goal of the rule is not fulfilled.

- Sensitivity power for most consumers, especially consumers, officials, commercial and industrial importance of the electricity distribution companies in the electricity supply will double. Because the distribution companies providing services in the electricity industry are the end points. This social and political power to the distribution companies is indescribable. This power can be a good tool to bring social pressure, political and even economic pressures. The private sector can thereby falsely demand the right or enforce the rule. If the monopoly of the pressures are more inclusive, it will be a security situation. In particular, its political direction and orientation prevail.

- Power outages, debtor customers already interact with the electricity distribution companies and customers do bilaterally. The quality of the electricity distribution companies relies on the social culture of customer interaction with expert staff. That is why the current debt is stagnant and the percentage of non-receipt of one hundred percent energy trading occurs.

- In case of failure of the private sector, the disadvantages mentioned in Section 2 will be achieved. In the case of monopoly, management of all distribution companies failed to apply, and can cause undesirable results that are difficult to restore.

- Knowledge of electrical distribution systems, and also technical, economic, social and managerial model in the world still has not established itself. In this case, the use of a variety of specialists make decisions and create a variety of different models are optimized. Thus, consulting competitive sectors, engineering support and better managed distribution models shape distribution. Monopolizing all decision-making to the specific experts eliminates the possibility of competition for obtaining the optimum model.

- Monopoly makes most of the assets of the electricity distribution industry, so that the company is closed as a whole. In the case of disqualification of the said company, it is hardly possible to find an alternative company. Also, an alternative price tender or exchange company may be less than the value of assets (due to a drop in the value of shares of the company's assets after the disqualification). In such cases, it is better to prevent monopoly and distribute the shares from the management of the system, and increase security transfer. The existence of the sense of the impossibility of disqualification can motivate the private sector in not trying to manage properly.

- As previously mentioned, the distribution system has several risks, many of which are local and regional ones. Analysis and management with a focus on a specific area can turn threats into opportunities and apply them to increase productivity. The distance monopoly means a lack of analysis and decision to risk management. Thus, the cost will increase and the service was that part.

- Monopoly in a company entrusted with the task of investment, but only if there is no monopoly of investment as many companies do. In this case, the higher investment and longer-term investment return can be expected.

- The lack of monopoly along with numerous companies as well as uncertainty about the company's lack of alternatives (if any possibility of disqualification due to lower services) make more efforts to create competition and incentives. Efforts to monitor the hidden rule of each other's private parts can help in the realization of its objectives. Meanwhile, the sale of shares and property stocks were higher.

\subsection{Review of procedures for the privatization of electricity distribution companies so far}

In this part, the process of privatization of electricity distribution companies in the last 20 years is examined and compared with the contents expressed in previous discussions, to provide paid flaws.

From 1998 onwards, 40 percent of regional power companies TAVANIR ${ }^{22}$ (In 1979, TAVANIR Company was established 
to undertake the responsibility for development of electric power generation, Transmission facilities and bulk Transaction of electricity with the Regional Electric Companies and Large industries) was transferred to the company (40 percent of shares of regional power companies and TAVANIR, the first charter company registration documents, preferred as their points of management and governance, and the distribution companies by the above-mentioned companies) (mentioned in Figure ${ }^{4}$ ). From 2003, the company SABA without special procedures has controlled at least 51 to 60 percent of the companies that were distributed. Until that distribution companies possesses assets (facilities, distribution network), not only in the form of five (commissioning) with regional electrical active service. Electric distribution, the price of assets transferred to the capital account, demand or liability for the distribution companies.

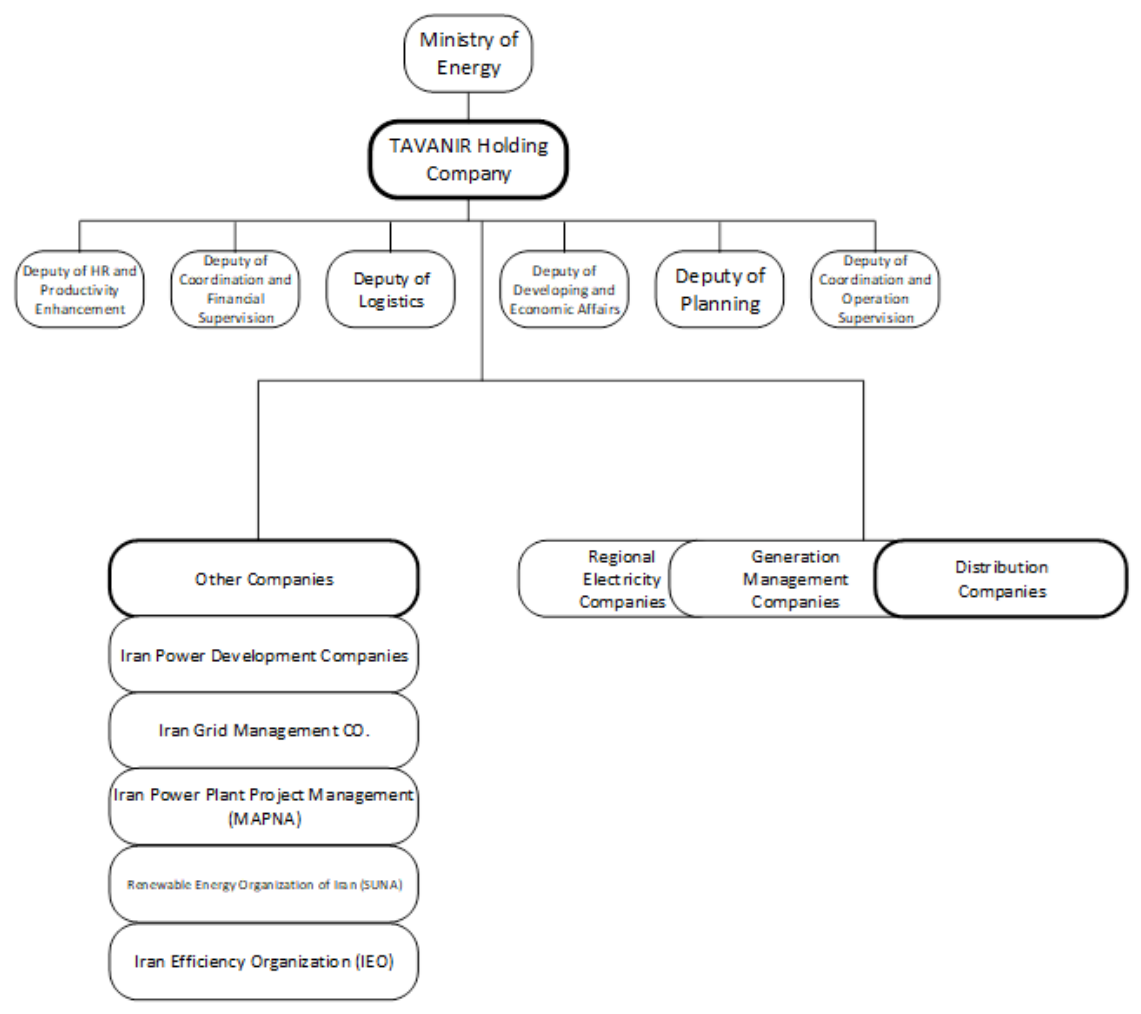

Fig 4. The general assembly of TAVANIR ${ }^{(22)}$

From 2003, the company SABA without special procedures has controlled at least 51 to 60 percent of the companies that were distributed. Until that distribution companies possesses assets (facilities, distribution network), not only in the form of five (commissioning) with regional electrical active service. Electric distribution, the price of assets transferred to the capital account, demand or liability for the distribution companies.

Then, the TAVANIR company has refrained from participating in the capital increase of its share in the SABA company (claims resulting from the transfer of assets), the company knows TAVANIR the materials themselves under hire-purchase contracts and 15 years, with 15 percent commission later also moderated, distribution companies are obliged to pay the property transfer, which reportedly has so far not paid any instalments of this for the TAVANIR company.

Act subsidies caused the price difference between electricity sales and cost assignment by the Government which were sold to distribution companies that receive energy prices paid. Failure to pay the difference between the gross losses caused by the government to improve the distribution companies. SABA, who has taken any measures in the field of distribution companies not to provide that from 2007 to 2012 the losses of distribution companies to participate shall be TAVANIR. This caused much of the debt distribution companies for the above-mentioned transfer of property (state property) losses by transferring the companies to be TAVANIR purchase.

The private nature of the SABA company is also significant: 49 percent of the shares owned by holding SATKAP disbanded SABA (state) and owned 98/49 percent MAHAB the award by private organizations and the remaining shares up to 100 percent of the three companies in the field of power industry belong.

It should be noted that the company's stock MAHAB respectively holding 49 percent owned and 26 percent owned SATKAP 
RAZAVI and 25 percent of the shrine of IMAM REZA (AS) is. Reportedly by government legislation will pass 49 percent in MAHAB QODS RAZAVI SATKAP been entrusted with the project approved by the Energy Minister in the eleventh Cabinet was cancelled. The 49 percent of the company's stock SATKAP SABA also been placed at the disposal of equity shares.

In this way, according to the above measures that SABA will resort to the methods of its full privatization and free from accountability to the state report. While about 60 percent of their assets transfers that have awarded SABA has not made any payments and is not an obligation. In this way, everyone is aware that at least commercial and financial information, the company realises that not only is not private, but also to non-tenure is state property, and this is exactly contrary to the objectives of Article 44 of the constitution and the guidelines of the Supreme Leader.

In addition to the above issues, SABA provided that the underlying stock TAVANIR preferred with significant material change of circumstances has led to the elimination of the statute of distribution companies, the de facto authority in the hands of distribution companies and TAVANIR Company, representative governance is powerless.

Thus, by removing the possibility of competition from other private sector management of the electricity distribution companies were assigned exclusively to the company SABA. It seems that, rather than a means to achieve the objectives of the privatization of the economy, enhance productivity and utility distribution companies, as well as achieving the goals of economic strength, it is considered to be objective, and regardless of the main objectives of privatization and the use of legal vacuum and interpretation of the provisions of the relevant legislation to a vote, so arbitrarily implemented.

So, we formed following stock companies and then transferred to the companies tricks SABA was transferred to the company, and then have the private nature. Such privatization is contrary to accepted methods. The possibility of competition and creating a monopoly in the management destroys its power distribution companies. The management of the electricity industry do not change, only the power management justifies the increased inefficiency.

\section{Conclusion}

The main drawbacks in the route towards the privatization can be categorized into the security issues, social impacts and economic consequences. In order to rectify the aforementioned ramifications, these complications need to be studied thoroughly ahead of time so that the governments can facilitate this transformation in a way that the socioeconomic effects can be managed diligently.

If this part is done properly and efficiently by the government, it paves the way towards a healthy transition the way both the companies and the public can benefit from the reform. The right legislations will be the key in order to minimize the risk of such actions if it has predicted all the possible complications ahead of time. Lack of the correct legislation will result in the mismanagement of the newly established private entities as they need to deal with some unnecessary and uncalled-for challenges. These requirements are discussed in the paper, the most important of which is to avoid monopoly on electricity distribution within the companies managed by the private sector.

\section{References}

1) Demoucelle P, Harrop C, Siddle R, Branden JCVD. Unbundling distribution and supply (Decoupler la Distribution et la Fourniture). Technical report by Bain \& Company. 2013;p. 1-18.

2) Joskow PL. Incentive regulation in theory and practice: electricity distribution and transmission networks. Economic Regulation and Its Reform: What Have We Learned. 2014;p. 291-344.

3) Pakistan GO. The causes and impacts of power sector circular debt in Pakistan. Study Commissioned by Planning Commission of Pakistan. Islamabad. 2013.

4) Moghimi SM, Hajjiah A, Dashti R. The Framework of Capital Governance in the Electrical Energy Distribution System. Indian J Sci Technol. $2018 ; 11: 2-5$.

5) Bostani A, Moghimi SM, Dashti R, Hashemi S. The Role of Preventive Major Maintenance in the Costs of Electric Energy Distribution Companies. Indian Journal of Science and Technology. 2018;p. 3-5.

6) Bostani A, Denidni, Tayeb. Design of a new ultra wideband antenna with band rejection in WLAN frequencies. IEEE antennas and propagation society international symposium. 2008;p. 1-4.

7) Energy Pioneers Ltd. Iran's power industry analysis: Investment risks and opportunities in post-sanctions era, Energy Pioneers Ltd. 2015.

8) Ibarra-Yunez A. Energy reform in Mexico: Imperfect unbundling in the electricity sector. Elsevier BV. 2015. Available from: https://dx.doi.org/10.1016/ j.jup.2015.06.009. doi:10.1016/j.jup.2015.06.009.

9) IBP. Indonesia Energy Policy, Laws and Regulation, Handbook. In: Strategic Information and Basic Laws: Indonesia. 2015;p. 1-296.

10) Mouton M. The Philippine electricity sector reform and the urban question: How metro Manila's utility is tackling urban poverty. Energy Policy. 2015;78:225-234. Available from: https://dx.doi.org/10.1016/j.enpol.2014.11.005. doi:10.1016/j.enpol.2014.11.005.

11) Hall D, Nguyen TA. Electricity Liberalisation in Developing Countries. SAGE Publications. 2017. Available from: https://dx.doi.org/10.1177/ 1464993416688824. doi:10.1177/1464993416688824.

12) Z XP. Restructured Electric Power Systems. John Wiley \& Sons. 2010;p. 1-309.

13) Domah P, Pollitt MG. 2001.

14) Besant-Jones JE. 2006. 
15) Rosenzweig MB, Voll SP, Pabon-Agudelo C. Power Sector Reform: Experiences from the Road. The Electricity Journal. 2004;17:16-28. doi:10.1016/j.tej.2004.10.002.

16) DG V, UN Department of Economic and Social Affairs, Division for Sustainable Development. The effects of power sector reform on energy services for the poor. 2005.

17) Wamukonya N. Power sector reform in developing countries: mismatched agendas. Energy Policy. 2003;31(12):1273-1289. doi:10.1016/s03014215(02)00187-8.

18) Fernando M, Rafael D, Wegner W. Power for Development: A Review of the World Bank Group's Experience with Private Participation in the Electricity Sector. Washington DC. 2003.

19) Effects of privatization: A case study from Cayirhan coal district, Turkey. Energy Policy. 2006;34:3017-3026.

20) Ebrahimi M, Siahkali H, Sarparandeh M, Bamdadian M, Abolfazli M. Privatization of electricity distribution sector in Iran. IEEE 8th GCC Conference \& Exhibition. 2015.

21) Yousefi GR, Kaviri SM, Latify MA, Rahmati I. Electricity industry restructuring in Iran. Energy Policy. 2017;108:212-226. doi:10.1016/j.enpol.2017.05.018.

22) https://www.pub.iaea.org/MTCD/Publications/PDF/cnpp2018/countryprofiles/IranIslamicRepublicof/IranIslamicRepublicof.htm. . 